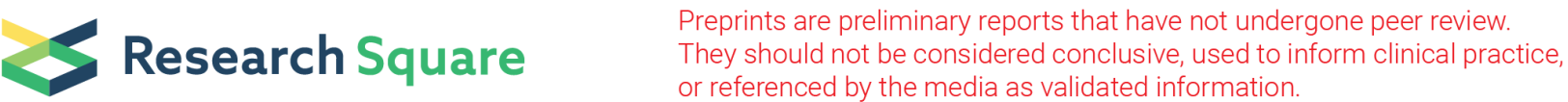

\section{Endovascular intervention for cerebral watershed infarction due to severe stenosis of the middle cerebral artery is safe and effective: A Retrospective Study}

\section{Huifang Xie ( $\nabla$ xhffhx@126.com )}

Southern Medical University Zhujiang Hospital https://orcid.org/0000-0003-3489-3452

\section{Zhenxing Yan}

Zhujiang Hospital

\section{Siqin Liu}

Zhujiang Hospital

\section{Xiongjun $\mathrm{He}$}

Shenzhen Hospital of southern medical university

\section{Liang Zhang}

Shenzhen hospital of Southern medical university

\section{Kaifeng Li}

Shenzhen hospital of Southern Medical university

\section{Yaowei Huang}

Southern Medical University Nanfang Hospital

\section{Wenxia Zheng}

Zhujiang Hospital

\section{Yuying Su}

Zhujiang Hospital

\section{Yiting Deng}

Zhujiang Hospital

\section{Yajie Liu}

Shenzhen hospital of Southern Medical university

\section{Research article}

Keywords: Watershed cerebral infarction, Low perfusion, Middle cerebral artery, Intravascular intervention, Neurocognitive function

Posted Date: October 21st, 2019

DOI: https://doi.org/10.21203/rs.2.16255/v1 
License: (우 (i) This work is licensed under a Creative Commons Attribution 4.0 International License. Read Full License 


\section{Abstract}

Introduction The aim of this study was to compare the clinical outcomes of standard drug therapy and endovascular intervention for cerebral watershed infarction (WSI) due to severe stenosis of the middle cerebral artery.Methods 86 patients with WSI due to severe stenosis of middle cerebral artery were included 46 endovascular intervention patients and 40 standard drug patients. Clinical data were collected at the time of admission, discharge, and the 90-day return to the hospital for review.

Results At the time of admission, there were no significant differences in the baseline data of age, gender, blood pressure, blood glucose, blood lipid, NIHSS, MOCA, or lifestyle characteristics such as smoking and drinking history $(P>0.05)$.At 90 days after discharge, there were statistically significant differences in NHISS score(3.20 \pm 1.65 and $4.35 \pm 2.63, P=0.028)$, mRS score $(0.69 \pm 0.81$ and $1.20 \pm 0.96, P=0.01)$ and MOCA score $(21.24 \pm 3.72$ and19.02 $\pm 3.48, P=0.006)$ between the two groups.

Conclusion The endovascular intervention for WSI due to severe stenosis of the middle cerebral artery has similar periprocedural complications and better outcomes compared to standard drug therapy.

\section{Background}

While there is a high incidence of extracranial carotid artery stenosis in the American population, the incidence of intracranial atherosclerotic stenosis is high in the Asian population(1). Recently, the preferred standard drug therapy and intravascular intervention are the two treatments for intracranial atherosclerotic stenosis; however, which treatment method provides a more satisfactory clinical outcome remains controversial. In 2007, it was first proposed that balloon dilation and stent implantation might be effective in the treatment of intracranial vascular stenosis(2). Subsequent SIMMPRIS studies indicated that WINGSPAN stent implantation in patients with intracranial atherosclerotic stenosis had a rather high risk of complications and mortality(3). In response to SIMMPRIS and in order to further verify the efficacy and safety of intravascular intervention, Zhongrong et al. conducted a study of intracranial artery stenosis in China. This Chinese study showed that the mortality rate within 30 days was only $4.3 \%(13 / 300$ cases), which was lower than that of the SAMMPRIS study(4). Therefore, this study demonstrated that it is safe and feasible to conduct intracranial artery interventional therapy by experienced surgeons by strictly selecting appropriate patients. However, even if the probability of complications is not as high as previously expected, endovascular intervention for severe atherosclerotic stenosis of intracranial arteries is still a high-risk operation, and we should focus on the long-term benefits and clinical prognosis of patients receiving this intervention. Considering the differences of race, geographical location, skill and experience of surgeons at different medical centers, and the rapid progress of scaffold materials and other factors, we planned to set strict criteria for enrollment and to screen patients suitable for intracranial vascular interventional therapy. We focused on observing the clinical prognosis of patients-such as cognitive function, language ability, limb function-in order to obtain more objective experimental results in this retrospective follow-up study.

Cerebral watershed infarction(WSI) means ischemic lesions between two non-anastomosing main arterial territories. Cerebral watershed infarction(WSI) can be divided into three types: cortical watershed infarction(CWI; or external watershed infarction) ,internal watershed 
infarction(IWI; or subcortical watershed infarction), and mixed-type(5).Internal watershed infarctions(IWI) were included in this study. Internal watershed infarctions(IWI) often involves severe stenosis or occlusion of one or more intracranial artery冋especially the middle cerebral artery in china. The blood perfusion of IWI in watershed area is relatively weak, may reduce the risk of high perfusion and brain hemorrhage after endovascular intervention and the watershed area is more likely to form infarct penumbra, which may lead to more functional recovery of brain cells and improve the prognosis after endovascular intervention(6).Therefore we selected internal watershed infarction(IWI) with severe middle cerebral artery stenosis to compare the clinical outcomes of standard drug therapy and endovascular intervention.

\section{Patients And Methods}

\subsection{Patients}

We retrospectively collected clinical data of patients with internal watershed infarction at Zhujiang Hospital of Southern Medical University from January 1, 2012, to June 30, 2018. All patients were required to complete routine angiography, magnetic resonance(MRI) and cerebral blood perfusion imaging(CTP). The degree of the stenosis of the middle cerebral artery was measured by digital subtraction angiography(DSA).

The inclusion criteria were as follows:(1)18-85 years old;(2)symptomatic middle cerebral artery stenosis (70-99\%);(3)MRI imaging showed internal watershed infarction, determined by two neurologists with more than 5 years of experience; and(4)no new ischemic events occurred within 1 week.

The exclusion criteria were as follows:(1) Vasculitis, muscle fiber dysplasia, and other nonatherosclerotic stenosis;(2)dementia had been clearly diagnosed in the past $(3)$ a known bleeding predisposition; (4)mRS $\geq 3$; and (5)MORI type-C lesions;

Patients were divided into groups A and B (A: endovascular intervention group; B: standard drug group) according to the principle of voluntary selection of follow-up treatment options .Demographic and clinical characteristics of the two groups-including age, gender, hypertension, hyperlipidemia, diabetes mellitus, coronary heart disease, smoking, and drinking-were collected. All patients at admission, discharge, and three months after discharge were measured for their scores on the NIHSS, mRS, and MOCA. Appropriate stents were used accroding to vascular conditions and responsible lesions in all endovascular intervention groups.

\subsection{Intervention Protocols}

Patients in standard drug group took aspirin (100 mg) and clopidogrel (75 mg) daily for three months and adjusted to either after three months. Patients in endovascular intervention group were chosen for appropriate stenting and took aspirin and clopidogrel dual anti-platelet aggregating drugs for six months after surgery, and then adjusted to aspirin or clopidogrel treatment after six months. Atorvastatin calcium was additionally given at $20 \mathrm{mg}$ QD in two groups. Intracranial middle cerebral artery stent implantation was performed under local anesthesia by two experienced neuro interventionists. First, an 8F arterial sheath was punctured into the femoral artery using the Seldinger technique. The catheter was placed into the cranial segment, angiography was performed to reevaluate the stenosis rate of the stenosis vessel length and diameter, and the microcatheter and micro guide wire were passed through the stenosis lesions under the path map. After the removal of the micro guide wire, microcatheter angiography confirmed that the microcatheter was located in the true vascular lumen. Then, the guidewire was 
exchanged, and the lesion site was expanded by the gateway balloon. Finally, appropriate stents were selected according to the characteristics of the lesions during the periprocedural period. Atropine and dopamine were used if patients underwent descent of heart rate or blood pressure. Systolic pressure was controlled to be at the level of about $80-90 \%$ of pre-endovascular treatment. 2.3. Clinical Evaluation and Follow-Up

All patients were advised to come back and see their doctor three months after discharge to check for the recurrence of cerebral infarction or cerebral hemorrhage. The clinical data-such as the occurrence of a second stroke, NHISS score, mRS score, MOCA score $\mathrm{CT}$ perfusion parameterswere collected at admission, discharge, and three months after discharge. Periprocedural complications were documented, including any periprocedural ischemic stroke, hyper perfusion syndrome, cerebral hemorrhage, or death within 90 days after endovascular intervention.

\subsection{Statistical Analysis}

SPSS20.0 software was used to analyze the data. The measurement data are presented as mean \pm SD. The means of NIHSS, mRS, and MOCA scores in the two groups were compared by two independent sample $t$ tests. Post-treatment NIHSS scores were compared by two-paired $t$ tests. Age, gender, hypertension, hyperlipidemia, diabetes mellitus, coronary heart disease, smoking, and alcohol abuse in the two groups were assessed using chi-square statistics. A $P$ value of less than 0.05 was considered statistically significant.

\section{Results}

\subsection{Baseline Data}

otal of 86 patients were enrolled in the present study. There were 46 patients in endovascular ərvention group, including 36 males and 10 females, with an average age of $60.21 \pm 7.37$ years. sre were 35 patients with a history of hypertension and 13 patients with a history of diabetes llitus. There was a total of 40 patients in standard drug group, including 23 males and 17 females, :d 40-70 years, with an average age of $63.30 \pm 8.27$ years. There were 31 patients with a history hypertension and 16 patients with a history of diabetes. Baseline data of all enrolled patientsluding age, gender, and previous instances of hypertension, diabetes, coronary heart disease, serlipidemia, smoking, and drinking-and NIHSS/mRS/MOCA scores at admission were not tistically different between the two groups $(\mathrm{P}>0.05)$ (Table 1$)$. sle1.Baseline data of all enrolled patients at admission 


\begin{tabular}{|c|c|c|c|}
\hline & $\begin{array}{l}\text { Endovascular intervention group ( } \mathrm{n} \\
=46 \text { ) }\end{array}$ & $\begin{array}{l}\text { Standard drug group }(\mathrm{n}= \\
40)\end{array}$ & $\begin{array}{l}\mathrm{P} \\
\text { value }\end{array}$ \\
\hline & $60.21 \pm 7.37$ & $63.30 \pm 8.27$ & $0.071^{\mathrm{a}}$ \\
\hline \multicolumn{4}{|l|}{ ler } \\
\hline & 36 & 23 & \multirow[t]{2}{*}{$0.061^{b}$} \\
\hline ale & 10 & 17 & \\
\hline ical history & & & \\
\hline rtension & 35 & 31 & $0.622^{\mathrm{b}}$ \\
\hline rlipemia & 15 & 18 & $0.602^{\mathrm{b}}$ \\
\hline ates mellitus & 13 & 16 & $0.577^{\mathrm{b}}$ \\
\hline $\begin{array}{l}\text { lary } \quad \text { heart } \\
\text { ise }\end{array}$ & 13 & 14 & $0.847^{\mathrm{b}}$ \\
\hline ing & 19 & 17 & $0.739^{\mathrm{b}}$ \\
\hline Iol abuse & 15 & 17 & $0.276^{\mathrm{b}}$ \\
\hline $\begin{array}{l}\text { is score at } \\
\text { ssion }\end{array}$ & $5.71 \pm 1.91$ & $5.75 \pm 1.66$ & $0.933^{\mathrm{a}}$ \\
\hline $\begin{array}{l}\text { score at } \\
\text { ssion }\end{array}$ & $1.54 \pm 0.503$ & $1.60 \pm 0.496$ & $0.602^{\mathrm{a}}$ \\
\hline $\begin{array}{l}\text { A score at } \\
\text { ssion }\end{array}$ & $19.00 \pm 3.36$ & $20.70 \pm 3.05$ & $0.352^{\mathrm{a}}$ \\
\hline
\end{tabular}

\section{independent sample t tests; b-chi-square statistics}

. Complications

patients in group A (endovascular intervention group) received stent angioplasty of the middle ebral artery within one week after admission. Postoperatively, one patient had a microhemorrhage the area of the ipsilateral external capsule. Fortunately, there was little bleeding $(2-3 \mathrm{ml})$. After od absorption, the patient was transferred to the rehabilitation physiotherapy department for limb ctional exercise. Another patient presented speech impairment after anesthesia, which gradually sroved after about $20 \mathrm{~h}$. No new ischemic lesions were found during CT reexamination, and nsient ischemic attack (TIA) during the operation was also considered. The success rate of lovascular intervention group was $100 \%$, and the incidence of perioperative complications was $5 \%$. Successful surgery was defined as a successful stent release with less than $50 \%$ residual nosis.

e of the patients in group B(standard drug group)developed aggravation during hospitalization$\mathrm{h}$ further aggravation of limb weakness and expression of disordered speech-and was later nsferred to the respiratory intensive care unit due to a complication of collapsed pneumonia. ther patient suffered recurring limb weakness four days after hospitalization, which rapidly reloped to partial limb paralysis. MRI examination confirmed that the patient had an arterial lusion with a new large area infarction, but the patient's condition gradually stabilized after drug atment. The incidence of secondary ischemic events was $5.26 \%$ in standard drug group after the it admission. Surprisingly, no patients in either group had a recurrent TIA or were admitted to the ;pital with a second stroke between discharge and their review 90 days later.

. Image Characteristics 
All patients underwent CT perfusion imaging(CTP) examination. Compared with magnetic resonance perfusion weighted imaging(PWI), CT perfusion is more rapid and economical, which is more suitable for the majority of Chinese patients. Therefore, CT perfusion imaging was selected in this study. There was low blood-flow perfusion in IWI, and the focal core-necrosis area did not match the low-perfusion area $>70 \%$ (according to European stroke society).Transcranial vascular morphology included MORI type-A lesions in 55 cases (74.32\%), and MORI type-B lesions in 19 cases (25.68\%).Figure 1 shows a patient with an internal watershed cerebral infarction. DSA of the patient indicated severe right middle cerebral artery stenosis. High resolution MRI of the patient showed that the right middle cerebral artery wall was significantly thickened and strengthened. Also, CTP of the patient suggested decreased perfusion in the right basal ganglia area and radiated crown. Taken his severe clinical manifestations and informed consent signed up by his family member into account, we performed this intervention, for which his CTP perfusion coefficient increased and he got a good prognosis.

Figure 1. A: small areas of core necrosis (internal watershed cerebral infarction); B: preoperative right middle cerebral artery angiography; C: High resolution MRI of the right middle cerebral artery aD:preoperative MTT; E: preoperative TTP; F:preoperative CBV; G: preoperative CBF; $\mathrm{H}$ :postoperative right middle cerebral artery; I:postoperative TTP; J: postoperative MTT; K: postoperative CBV; L: postoperative CBF;

Table2:CTP perfusion parameters before and after endovascular intervention

\begin{tabular}{|c|c|c|c|c|c|c|c|c|}
\hline & \multicolumn{4}{|c|}{ Preoperation } & \multicolumn{4}{|c|}{ Postoperation } \\
\hline & $\begin{array}{l}\text { Right } \\
\text { radiated } \\
\text { crown }\end{array}$ & $\begin{array}{l}\text { Left radiated } \\
\text { crown }\end{array}$ & $\begin{array}{l}\text { Right } \\
\text { basal } \\
\text { ganglia }\end{array}$ & $\begin{array}{l}\text { Left } \\
\text { basal } \\
\text { ganglia }\end{array}$ & $\begin{array}{l}\text { Right } \\
\text { radiated } \\
\text { crown }\end{array}$ & $\begin{array}{l}\text { Left radiated } \\
\text { crown }\end{array}$ & $\begin{array}{l}\text { Right } \\
\text { basal } \\
\text { ganglia }\end{array}$ & $\begin{array}{l}\text { Left } \\
\text { basal } \\
\text { ganglia }\end{array}$ \\
\hline (1) & 1.19 & 1.37 & 1.60 & 1.61 & 1.35 & 1.39 & 1.61 & 1.62 \\
\hline \multirow{3}{*}{ g.min) } & 10.38 & 13.86 & 15.7 & 19.4 & 12.6 & 14.02 & 17.8 & 20.2 \\
\hline & 9.25 & 8.75 & 8.39 & 6.49 & 8.92 & 8.77 & 6.37 & 7.02 \\
\hline & 15.82 & 15.0 & 14.9 & 13.8 & 13.6 & 15.2 & 13.4 & 13.6 \\
\hline
\end{tabular}

\section{Functional Outcomes}

yure2. NIHSS score at different periods in the two groups.

ure3. mRS score at different periods in the two groups.

ure4. MOCA score at different periods in the two groups.

эre was no statistically significant difference in the NIHSS scores in standard drug group between nission and discharge $(\mathrm{P}=0.526)$. However, the NIHSS scores reviewed after 90 days in standard 
Ig group showed a significant improvement trend, and the comparison between the reviewed ISS scores and the discharged NIHSS scores was statistically significant $(\mathrm{P}<0.001)$. In lovascular intervention group, the NIHSS scores on admission, discharge, and review at 90 days re all statistically significant $(\mathrm{P}<0.001)$. The NIHSS score 90 days after discharge was used to npare whether there was a difference between endovascular intervention group and standard drug up $(P=0.028)$. The mRS score after three months of treatment was slightly improved compared $\mathrm{h}$ that at the time of admission in both groups. For further subdivided comparison between the two ups, the mRS score after three months of reexamination between endovascular intervention group l standard drug group showed statistical significance $(P=0.01)$. The MOCA score of patients in two groups was generally low at admission. There was a statistically significant difference in the ICA score between admission and 90 days after treatment in the two groups (endovascular эrvention group: $\mathrm{P}<0.001$; standard drug group: $\mathrm{P}=0.005)$. The difference in the preoperative ICA score of the two groups was not statistically significant $(P=0.352)$, but the MOCA score three nths after discharge showed a statistically significant difference ( $\mathrm{P}=0.006$;Figure4).

\section{Discussion}

Cerebral watershed infarction(WSI),ischemic lesions between two non-anastomosing main arterial territories, accounts for about $10 \%$ of all cerebral infarction patients(7). WSI can be divided into three types: cortical watershed infarction(CWI; or external watershed infarction), internal watershed infarction(IWI; or subcortical watershed infarction), and mixed-type. The disease is caused by micro emboli, low blood perfusion, or a combination of hemodynamic abnormalities. Distinct from cerebrovascular disease caused by perforator vessel disease, WSI is a common disease due to severe arterial stenosis and poor collateral circulation. Among them, IWI is often indicated severe intracranial vascular stenosis or hemodynamic abnormalities[8]. The clinical manifestations of WSI are diverse. Moreover, the symptoms of nerve-function defects mainly depend on the location and degree of infarction. From the perspective of pathogenesis, perfusion abnormalities associated with the diffusion lesions can be divided into three types: normal perfusion, localized-perfusion deficit (matching the area of restricted diffusion), and extensiveperfusion deficit (involving one or more vascular territories).Focal hypoperfusion injury matching the dispersion pattern is more common in patients with embolism(8).Severe hypoperfusion injury that does not match the dispersion pattern often involves severe stenosis or occlusion of one or more blood vessels. Such patients are prone to form internal watershed infarction(IWI; or subcortical watershed infarction), which is shown by imaging as the perfusion area that does not match the core necrosis, and most of the clinical symptoms are progressive with poor prognosis. Clinically, magnetic resonance perfusion weighted imaging(MR-PWI) and magnetic resonance diffusion weighted imaging(MR-DWI), or CTP, are often used to determine the pathogenesis of WSI(9).But compared with magnetic resonance PWI-DWI, CT perfusion is more rapid and economical, which is more suitable for the majority of Chinese patients.

Currently, drug intensive therapy is still the preferred treatment for intracranial atherosclerotic stenosis. In patients with severe intracranial artery stenosis accompanied by low perfusion, stenting can reduce the risk of stroke recurrence(10). However, SIMMPRIS considered that intracranial stent treatment had a high incidence of complications, as well as no greater benefit compared to that of drug treatment alone. In DEFUSES,DAWNS studies and our clinical observation ,PWI-DWI of cranial MRI have shown that when the core infarction lesion is 
significantly mismatched with the hypoperfusion area, stenting can greatly improve the clinical neurological defects of patients(11).Therefore, when patients have insufficient collateral circulation compensation due to severe intracranial artery stenosis, and intracranial imaging shows only small lesions but a large area of low perfusion, the effect of blood flow recanalization should be equivalent to or prior to thrombectomy. In our present research, we verified the feasibility of this theory by preoperative CTP examination in the low-perfusion area and showed that two groups of patients had longer TTP and MTT on the lesion side than that on the healthy side, while CBV and CBF were reduced. The endovascular intervention group had significantly improved CBF/CBV, and shortened TTP/MTT, which were shown in the postoperative review of CTP. However, for the patients in standard drug group, the CTP perfusion coefficient was basically the same as that at the time of admission. The data in Figure 1 and Table 1 demonstrate that angioplasty could improve and reverse the low-perfusion state of the cerebral hemisphere.

We compared and analyzed NIHSS score and mRS score of endovascular intervention group and standard drug group at the 90-day review and found that the clinical prognosis of patients in endovascular intervention group was better than that in standard drug group. This result relates to the fact that the ischemic penumbra was quickly saved in endovascular intervention group after the change of hypoperfusion status. Second, cerebral edema is an important pathophysiological process of cerebral ischemia reperfusion injury. Jie et al.(12) found that cerebral tissue edema was obvious after ischemia for $60 \mathrm{~min}$ and reperfusion for $48 \mathrm{~h}$. At the same time, the expression of matrix metalloproteinase-2 and -9 increased and the expression of tight-junction proteins decreased. Oxidative stress induced by free radicals also plays an important role(13).

Epidemiological investigational data show that about $30 \%$ of stroke patients will develop dementia within one year after the occurrence of stroke events(14). Previous studies have shown that patients with severe carotid artery stenosis are in a state of cerebral hypoperfusion for a long period of time, resulting in a decrease in the active cells in the nerve area of their blood supply, thus affecting the cognitive function of patients(15). With the improvement of cerebral blood flow, the perfusion state changed, and the degree of cognitive impairment decreased. Wand et al. (16)and Cheng et al.(17)used MR perfusion imaging and CT perfusion imaging, respectively, to reflect the perfusion improvement before and after carotid artery stent (CAS). These studies found that with the improvement of perfusion, cognitive dysfunction was significantly improved, indicating that cerebral hypoperfusion was related to the cognitive dysfunction in ACS patients. Therefore, in the present study, we focused on the cognitive changes in both groups at admission and review. Alvadori et al.(18)showed that the MOCA scale can be used to screen for cognitive impairment in patients with acute stroke, which is more sensitive than Mini-mental State Examination(MMSE). Similarly, MOCA has been shown to be a sensitive assessment tool in the assessment of cognitive impairment caused by carotid artery stenosis(19). Based on previous work, we used the MOCA scale to evaluate the cognitive function of patients with cerebral infarction. In the present study, patients in endovascular intervention group generally had a promising prognosis, including improvement of intelligence .Currently, the commonly recognized mechanisms mainly involve cerebral micro emboli and cerebral hypoperfusion, which can lead to resting cerebral infarction, white matter lesions, and other brain tissue damage(20). However, there are some other studies with conflicting findings. After 334 patients with cognitive impairment were followed up for two to three years by Benedictus et al., 16\% of them developed cognitive impairment with progressive aggravation, which is related to the degree of white matter lesions(21). Lin CJ et al. 
(22)found that, in patients with severe atherosclerotic stenosis, there are many types of damage to brain network-connection structure and that the bilateral hemispheric long-distance nonhippocampal pathway has been damaged before the occurrence of cognitive dysfunction. This suggests that asymptomatic patients with severe carotid artery stenosis have had brain network connectivity destroyed at the subclinical stage.

\section{Limitations}

There are several limitations to our study. Firstly, the sample size is insufficient. Secondly, interventional therapy may produce new micro emboli or temporary hypoperfusion, but the benefits of the eventual opening of the vessels were sufficient to mask these risks .Lastly, our study was retrospective follow-up study. The retrospective design and the lack of randomization in grouping patients may bias our results.

\section{Conclusions}

Watershed infarcts have a definite relationship with low perfusion caused by atherosclerotic stenosis of the great arteries, especially the middle cerebral artery. In endovascular intervention group, imaging confirmed that postoperative perfusion was improved, and their NIHSS and MOCA scores were increased and their mRS score was decreased, which indicated that the patients in endovascular intervention group had better outcomes. Additionally, we conclude that endovascular intervention is safe for patients with IWI due to severe stenosis of the middle cerebral artery, but this finding requires corroboration from further multi-center large sample RCTs.

\section{Abbreviations}

WSI cerebral watershed infarction

CWI cortical watershed infarction

IWI internal watershed infarction

CTP cerebral blood perfusion imaging

DSA digital subtraction angiography

TIA transient ischemic attack

PWI magnetic resonance perfusion weighted imaging

DWI magnetic resonance diffusion weighted imaging

TTP Transit time to peak

MTT Mean transit time

CBV Cerebral blood flow

CBF Cerebral blood volume

CAS carotid artery stent

\section{Declarations}

\section{Acknowledgement}

We thank LetPub (www.letpub.com) for its linguistic assistance during the preparation of this manuscript.

\section{Funding}


No funding or sponsorship was received for this study or publication of this article.

\section{Availability of data and materials}

The datasets used and/or analyzed during the current study are available from the corresponding author on reasonable request.

\section{Authors' contribution}

Zhenxing Yan and Siqin Liu contributed equally to this article and thus share the first coauthorship. All authors approved the final manuscript.

\section{Ethics approval and consent to participate}

This study was conducted in accordance with the Declaration of Helsinki. This study was conducted with approval from the Ethics Committee of Zhujiang Hospital of Southern Medical Universitylethics approval reference number:2014-SJNK-002).

Consent for publication

All named authors meet the International Committee of Medical Journal Editors (ICMJE) criteria for authorship for this article, take responsibility for the integrity of the work as a whole, and have given their approval for this version to be published.

\section{Competing interests}

The authors declare that they have no competing interests.

\section{References}

1. Qureshi AI, Feldmann E, Gomez CR, Johnston SC, Kasner SE, Quick DC, et al. Intracranial atherosclerotic disease: An update. ANN NEUROL. [Journal Article; Research Support, N.I.H., Extramural; Research Support, NonU.S. Gov't; Review]. 2009 2009-12-01;66(6):730-8.

2. Fiorella D, Levy EI, Turk AS, Albuquerque FC, Niemann DB, Aagaard-Kienitz B, et al. US multicenter experience with the wingspan stent system for the treatment of intracranial atheromatous disease: periprocedural results. STROKE. [Comparative Study; Journal Article; Multicenter Study; Research Support, Non-U.S. Gov't]. 2007 2007-03-01;38(3):881-7.

3. Derdeyn CP, Chimowitz MI, Lynn MJ, Fiorella D, Turan TN, Janis LS, et al. Aggressive medical treatment with or without stenting in high-risk patients with intracranial artery stenosis (SAMMPRIS): the final results of a randomised trial. LANCET. [Journal Article; Multicenter Study; Randomized Controlled Trial; Research Support, N.I.H., Extramural; Research Support, Non-U.S. Gov't]. 2014 2014-01-25;383(9914):333-41.

4. Miao Z, Zhang Y, Shuai J, Jiang C, Zhu Q, Chen K, et al. Thirty-Day Outcome of a Multicenter Registry Study of Stenting for Symptomatic Intracranial Artery Stenosis in China. STROKE. [Clinical Trial; Journal Article; Multicenter Study; Research Support, Non-U.S. Gov't]. 2015 2015-10-01;46(10):2822-9.

5. Li Y, Li M, Zhang X, Yang S, Fan H, Qin W, et al. Clinical features and the degree of cerebrovascular stenosis in different types and subtypes of cerebral watershed infarction. BMC NEUROL. [Journal Article]. 2017 2017-08-29;17(1):166. 

Carotid Artery Stenting for Symptomatic Cerebral Watershed Infarction due to Stenosis of the Proximal Internal Carotid Artery. BIOMED RES INT. [Comparative Study; Journal Article]. 2016 2016-01-20;2016:6241546.

7. Yong SW, Bang OY, Lee PH, Li WY. Internal and cortical border-zone infarction: clinical and diffusionweighted imaging features. STROKE. [Journal Article; Research Support, Non-U.S. Gov't]. 2006 2006-03$01 ; 37(3): 841-6$.

8. Bang OY, Lee PH, Heo KG, Joo US, Yoon SR, Kim SY. Specific DWI lesion patterns predict prognosis after acute ischaemic stroke within the MCA territory. J Neurol Neurosurg Psychiatry. [Journal Article; Research Support, Non-U.S. Gov't]. 2005 2005-09-01;76(9):1222-8.

9. Chaves CJ, Silver B, Schlaug G, Dashe J, Caplan LR, Warach S. Diffusion- and perfusion-weighted MRI patterns in borderzone infarcts. STROKE. [Journal Article]. 2000 2000-05-01;31(5):1090-6.

10. Stampfl S, Hartmann M, Ringleb PA, Haehnel S, Bendszus M, Rohde S. Stent placement for flow restoration in acute ischemic stroke: a single-center experience with the Solitaire stent system. AJNR Am J Neuroradiol. [Journal Article; Research Support, Non-U.S. Gov't]. 2011 2011-08-01;32(7):1245-8.

11. Albers GW, Lansberg MG, Kemp S, Tsai JP, Lavori P, Christensen S, et al. A multicenter randomized controlled trial of endovascular therapy following imaging evaluation for ischemic stroke (DEFUSE 3). INT J STROKE. [Clinical Trial, Phase III; Journal Article; Multicenter Study; Randomized Controlled Trial; Research Support, N.I.H., Extramural]. 2017 2017-10-01;12(8):896-905.

12. Jie P, Tian Y, Hong Z, Li L, Zhou L, Chen L, et al. Blockage of transient receptor potential vanilloid 4 inhibits brain edema in middle cerebral artery occlusion mice. FRONT CELL NEUROSCI. [Journal Article]. 2015 2015-0120;9:141.

13. Taskiran-Sag A, Yemisci M, Gursoy-Ozdemir Y, Erdener SE, Karatas H, Yuce D, et al. Improving Microcirculatory Reperfusion Reduces Parenchymal Oxygen Radical Formation and Provides Neuroprotection. STROKE. [Journal Article]. 2018 2018-05-01;49(5):1267-75.

14. Cullen B, Neill BO, Evans JJ, Coen RF, Lawlor BA. A review of screening tests for cognitive impairment. J Neurol Neurosurg Psychiatry. 2007(78):790-9.

15. Argaw AT, Asp L, Zhang J, Navrazhina K, Pham T, Mariani JN, et al. Astrocyte-derived VEGF-A drives bloodbrain barrier disruption in CNS inflammatory disease. J CLIN INVEST. [Journal Article; Research Support, American Recovery and Reinvestment Act; Research Support, N.I.H., Extramural; Research Support, Non-U.S. Gov't]. 2012 2012-07-01;122(7):2454-68.

16. KL H, Ho MY CC, SJ R, HF W, IC H, TY C, et al. Impact of Silent Ischemic Lesions on Cognition following Carotid Artery Stenting. EUR NEUROL. 2011(66):351-8.

17. Paraskevas KI, Giannoukas AD. Asymptomatic cerebral lesions after carotid artery stenting may not predict future cerebrovascular events but may be associated with cognitive impairment. JACC Cardiovasc Interv. [Letter; Comment]. 2013 2013-09-01;6(9):987-8.

18. Salvadori E, Pasi M, Poggesi A, Chiti G, Inzitari D, Pantoni L. Predictive value of MoCA in the acute phase of stroke on the diagnosis of mid-term cognitive impairment. J NEUROL. [Journal Article]. 2013 2013-09-01;260(9):22207.

19. Martinic-Popovic I, Lovrencic-Huzjan A, Demarin V. Assessment of subtle cognitive impairment in strokefree patients with carotid disease. ACTA CLIN CROAT. [Journal Article]. 2009 2009-09-01;48(3):231-40.

20. Balucani C, Silvestrini M. Carotid atherosclerotic disease and cognitive function: mechanisms identifying new therapeutic targets. INT J STROKE. [Journal Article; Review]. 2011 2011-08-01;6(4):368-9.

21. Benedictus MR, van Harten AC, Leeuwis AE, Koene T, Scheltens P, Barkhof F, et al. White Matter Hyperintensities Relate to Clinical Progression in Subjective Cognitive Decline. STROKE. [Journal Article; Research Support, Non-U.S. Gov't]. 2015 2015-09-01;46(9):2661-4.

22. Lin CJ, Tu PC, Chern CM, Hsiao FJ, Chang FC, Cheng HL, et al. Connectivity features for identifying cognitive impairment in presymptomatic carotid stenosis. PLOS ONE. [Journal Article; Research Support, Non-U.S. 


\section{Figures}
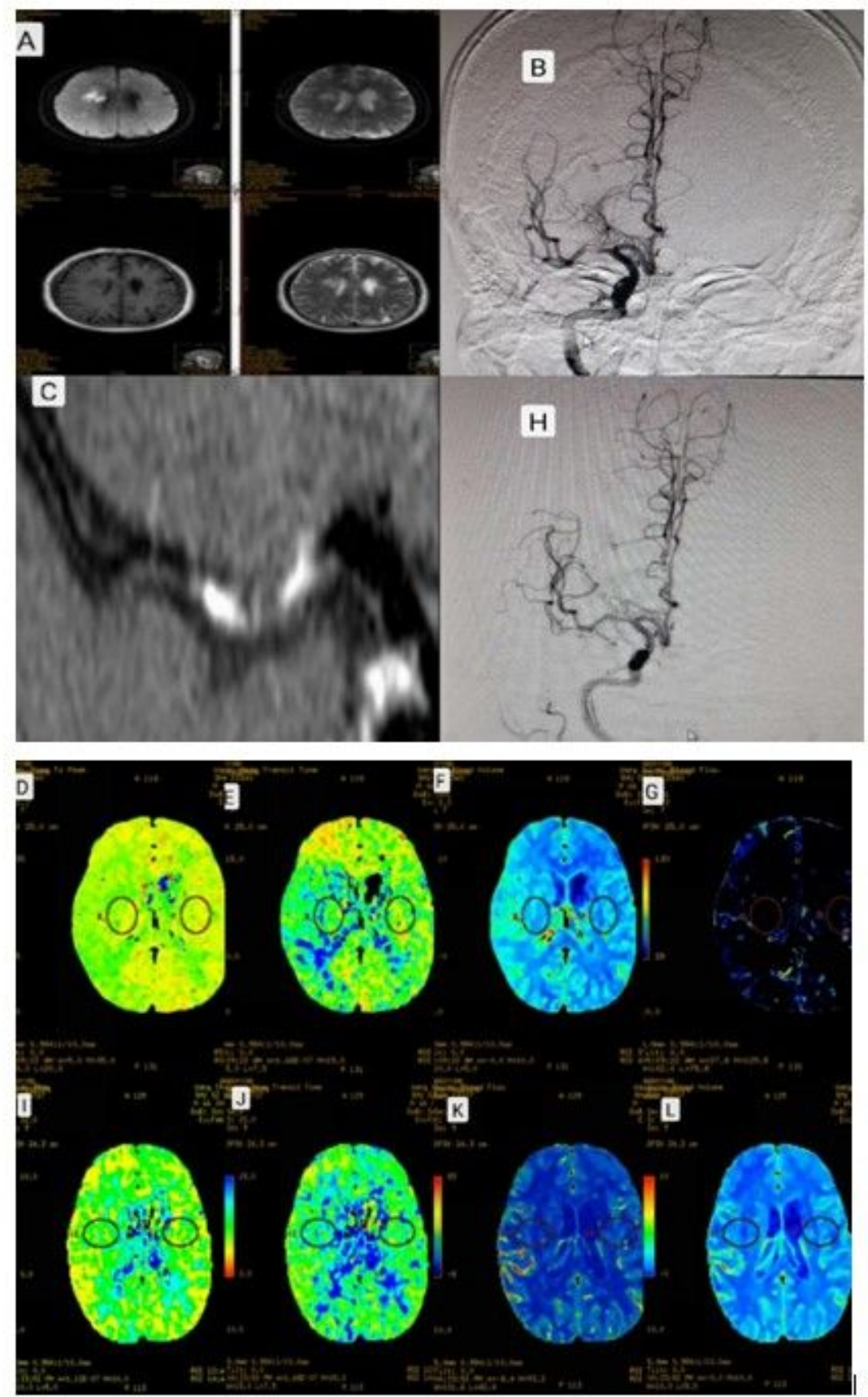

\section{Figure 1}

A: small areas of core necrosis (internal watershed cerebral infarction); B: preoperative right middle cerebral artery angiography; C: High resolution MRI of the right middle cerebral artery $\otimes \mathrm{D}$ :preoperative MTT; E: 
preoperative TTP; F:preoperative CBV; G: preoperative CBF; H:postoperative right middle cerebral artery; I:postoperative TTP; J: postoperative MTT; K: postoperative CBV; L: postoperative CBF;

\section{NIHSS score}

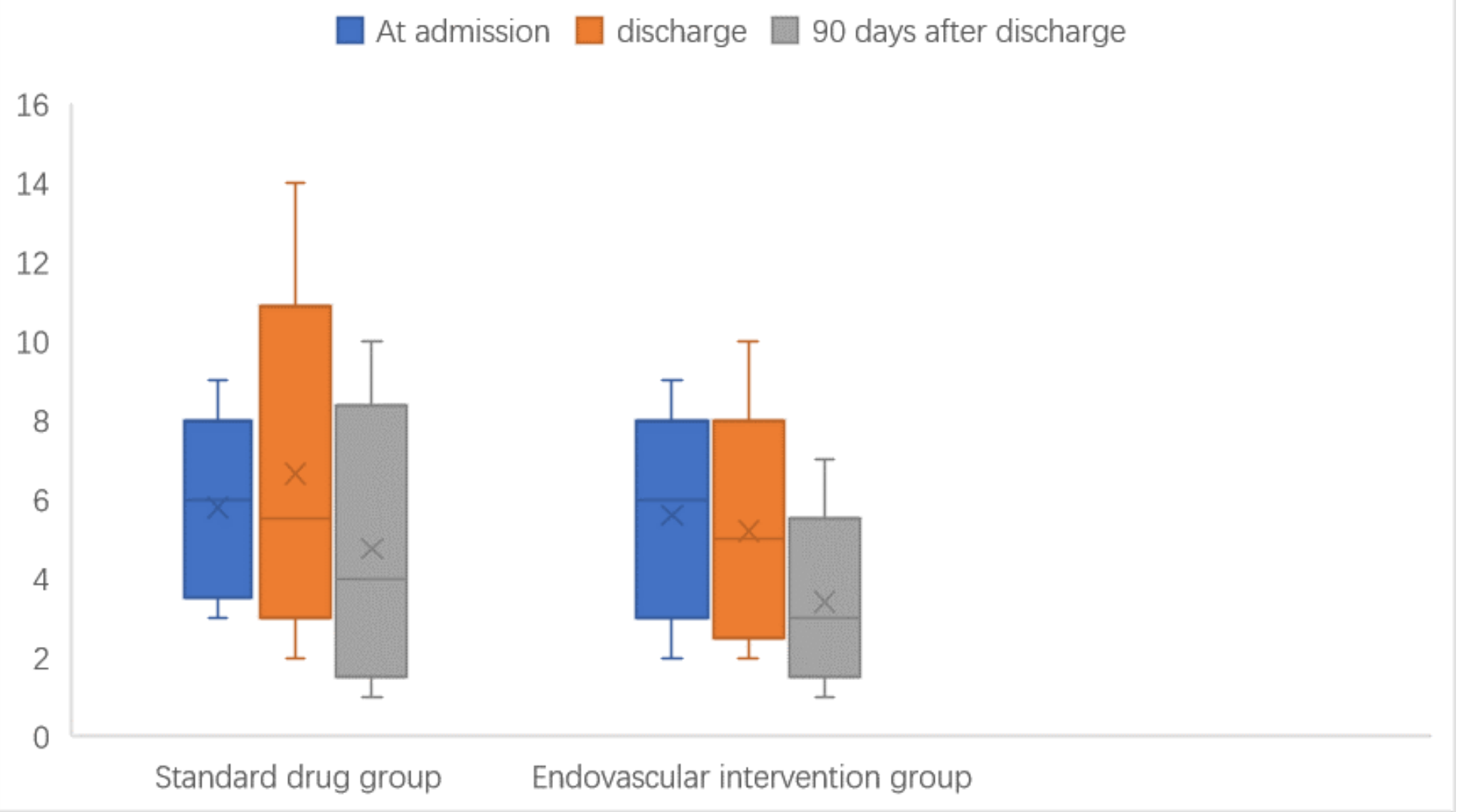

\section{Figure 2}

NIHSS score at different periods in the two groups. 


\section{mRS score}

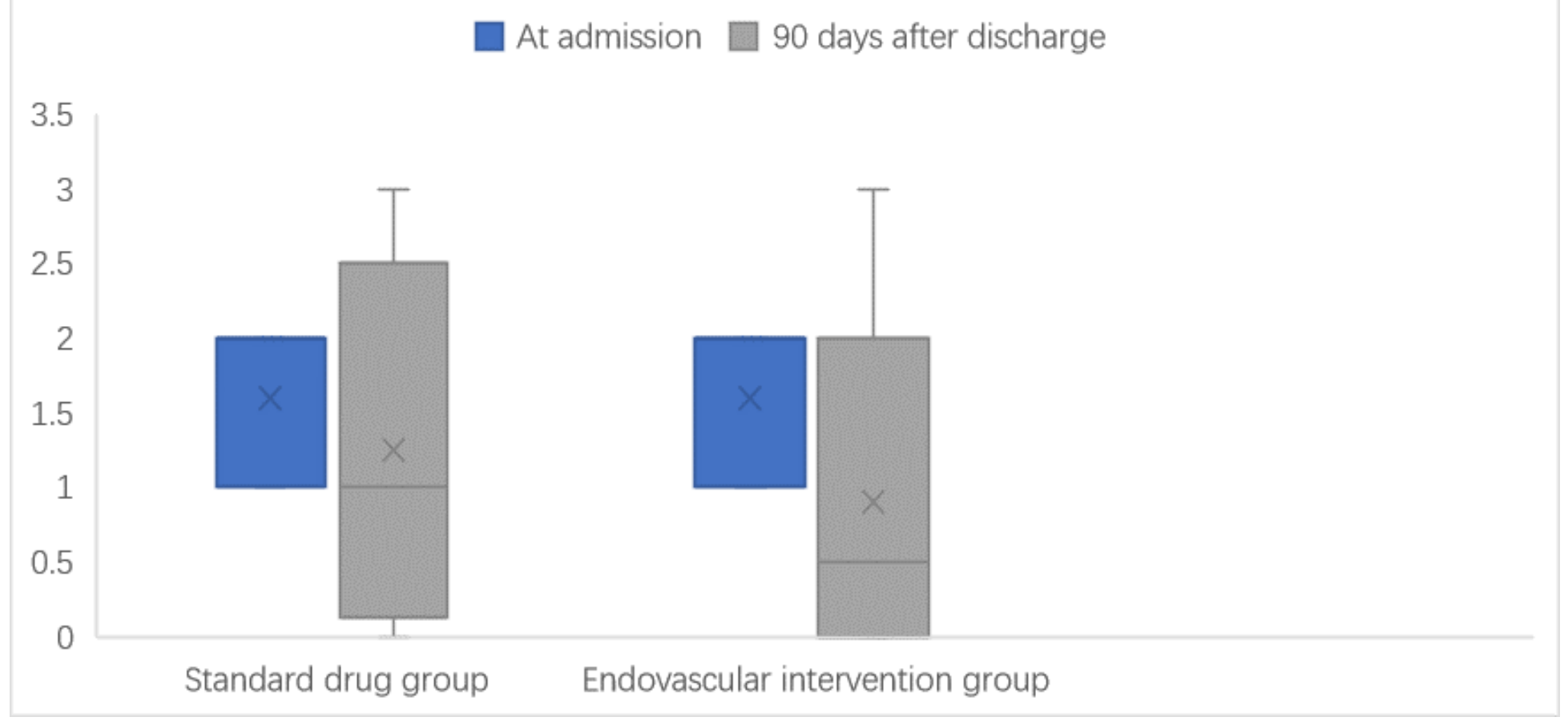

Figure 3

mRS score at different periods in the two groups. 


\section{MOCA score}

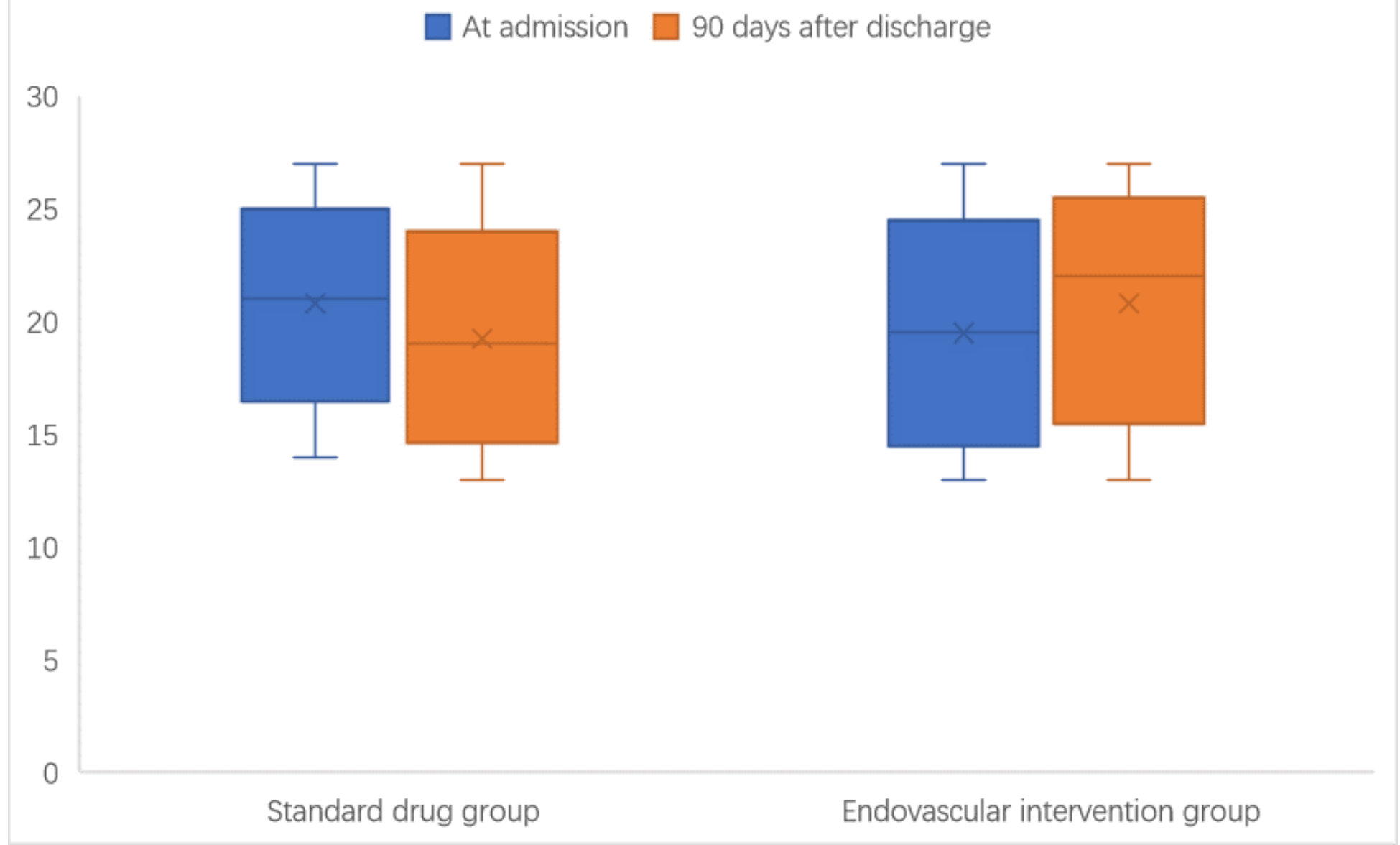

\section{Figure 4}

MOCA score at different periods in the two groups. 